\title{
Correction to: Studying micro dynamics in civil wars: introduction
}

\author{
Roos Haer · Johannes Vüllers • Nils B. Weidmann
}

Published online: 10 December 2019

(C) Arbeitsgemeinschaft für Friedens- und Konfliktforschung e.V. (AFK) und die Autoren 2019

\section{Correction to:}

\section{Z Friedens und Konflforsch 2019}

https://doi.org/10.1007/s42597-019-00018-9

The original version of this article unfortunately contains a mistake. The first sentence in section "3 Overview of the special issue" fifth paragraph should read:

"The paper by Krauser et al. focuses on examining the impact of international investment in the mining sector on female employment, and how this might foster grievances."

The online version of the original article can be found under https://doi.org/10.1007/s42597-01900018-9.

R. Haer $(\bowtie) \cdot J$. Vüllers

Leiden University, Leiden, The Netherlands

E-Mail: r.van.der.haer@fsw.leidenuniv.nl

J. Vüllers

E-Mail: j.vullers@fgga.leidenuniv.nl

N. B. Weidmann

University of Konstanz, Konstanz, Germany

E-Mail: nils.weidmann@uni-konstanz.de 